\title{
Removal of sulfamethoxazole (SMX) in sulfate-reducing flocculent and granular sludge systems
}

Qiu, Lin-Qing; Zhang, Liang; Tang, Kai; Chen, Guanghao; Kumar Khanal, Samir; Lu, Hui

Published in:

Bioresource Technology

Link to article, DOI:

10.1016/j.biortech.2019.121592

Publication date:

2019

Document Version

Peer reviewed version

Link back to DTU Orbit

Citation (APA):

Qiu, L-Q., Zhang, L., Tang, K., Chen, G., Kumar Khanal, S., \& Lu, H. (2019). Removal of sulfamethoxazole (SMX) in sulfate-reducing flocculent and granular sludge systems. Bioresource Technology, 288, [121592]. https://doi.org/10.1016/j.biortech.2019.121592

\section{General rights}

Copyright and moral rights for the publications made accessible in the public portal are retained by the authors and/or other copyright owners and it is a condition of accessing publications that users recognise and abide by the legal requirements associated with these rights.

- Users may download and print one copy of any publication from the public portal for the purpose of private study or research.

- You may not further distribute the material or use it for any profit-making activity or commercial gain

- You may freely distribute the URL identifying the publication in the public portal 


\section{Removal of sulfamethoxazole (SMX) in sulfate-reducing flocculent and granular sludge systems}

Lin-Qing Qiu ${ }^{\mathrm{a}, \mathrm{b}}$, Liang Zhang ${ }^{\mathrm{c}}$, Kai Tang ${ }^{\mathrm{d}}$, Guanghao Chen ${ }^{\mathrm{e}}$, Samir Kumar Khanal ${ }^{f}$ Hui Lu ${ }^{\mathrm{a}, \mathrm{b}, *}$ ${ }^{a}$ School of Environmental Science and Engineering, Sun Yat-sen University, Guangzhou, China ${ }^{b}$ Guangdong Provincial Key Laboratory of Environmental Pollution Control and Remediation Technology (Sun Yat-sen University), Guangzhou, China

'Advanced Environmental Biotechnology Centre, Nanyang Environment \& Water Research Institute, Nanyang Technological University, 50 Nanyang Avenue, Singapore, 639798, Singapore ${ }^{d}$ Department of Environmental Engineering, Technical University of Denmark, Bygningstorvet 115, 2800 Kgs., Lyngby, Denmark

${ }^{e}$ Department of Civil and Environmental Engineering, The Hong Kong University of Science and Technology, Clear Water Bay, Kowloon, Hong Kong

${ }^{f}$ Department of Molecular Biosciences and Bioengineering, University of Hawai'i at Mānoa, 1955 East-West Road, Honolulu, HI 96822, USA

*Corresponding author.

Email address: Ivhui3@mail.sysu.edu.cn 
Abstract

This study investigated sulfamethoxazole (SMX) removal and fate in sulfate-reducing up-flow sludge bed (SRUSB) reactors inoculated with sulfate-reducing bacteria (SRB) granules and flocs. The resilience of SRB granules and flocs against varying $\mathrm{pHs}$ and hydraulic retention times (HRTs) was also examined. SRB granules and flocs efficiently removed SMX from wastewater, which was significantly higher than the aerobic sludge. SRB granules achieved significantly $(p<0.05)$ higher SMX removal $(\sim 13.3 \mu \mathrm{g} / \mathrm{g}$ suspended solids (SS)-d) than the SRB flocs ( 11.2 $\mu \mathrm{g} / \mathrm{g}$ SS-d) during 150-day of SRUSB reactors operation. The SMX removal by both granules and flocs was mainly attributed to biodegradation. Sorption also contributed to SMX removal, in which aromatic protein-like substances of extracellular polymeric substances played important role in SMX removal. In addition, SRB granules showed higher resilience than SRB flocs against varying pHs and HRTs. Thus, SRB-mediated biological process, especially SRB granules, could be a promising biotechnology to remove SMX from wastewaters.

Keywords: Sulfamethoxazole (SMX), Sulfate reducing bacteria (SRB) granules and flocs, Biodegradation, Adsorption, Extracellular polymeric substances (EPS) 


\section{Introduction}

Sulfamethoxazole (SMX) is one of the extensively used antibiotics by humans, and for animal production and aquaculture (Zuccato et al., 2010, Zhang et al., 2017), and is frequently detected in aquatic environment (Heberer, 2002, Xu et al., 2011).

Owing to its slow degradation, SMX is highly persistence in the environment and has received increasing attention in recent years (Chen et al., 2015). Wastewater treatment plants (WWTPs) effluents, aquaculture effluent, digestate / biosolids and animal manures are the main sources of SMX entering into the environment (Joss et al., 2005). Conventional activated sludge (CAS) process is mainly aimed at removal of typical pollutants, such as organics, nitrogen and phosphorus, and is less effective in the removal of antibiotic compounds (Grandclement et al., 2017). Moreover, the process is highly energy intensive and generates large amount of biological sludge. Anaerobic process is cost-effective for treating high strength/high solids waste (water). However, the process is less effective in removing the antibiotics (Falås et al., 2016, Grandclement et al., 2017). The process is also less effective in removing carbon, nitrogen and phosphorus simultaneously. Thus, there is a critical need to develop an economical, effective and energy-efficient biological process for simultaneous removal of organic matters, nitrogen and phosphorus along with antibiotics. One of such innovative biotechnologies is Sulfate-reduction Autotrophicdenitrification and Nitrification Integrated (SANI) process, which has shown to reduce sludge generation by $60-70 \%$, energy consumption by $35 \%$ and $\mathrm{CO}_{2}$ emission by $36 \%$ compared to CAS process (Lu et al., 2012, Wu et al., 2016). 
Recently, sulfate-reducing bacteria (SRB)-mediated biological process has been employed to treat sulfate-laden pharmaceutical wastewater, and has shown better tolerance of SRB to high concentrations of pharmaceutical compounds compared to aerobic microbes (Mohan et al., 2005, Li et al., 2015). Several studies reported that SRB-enriched sludge flocs could efficiently remove antibiotics such as SMX and ciprofloxacin (CIP) from wastewater (Jia et al., 2017, Jia et al., 2018). Thus, SRB sludge system has the potential of treating wastewater containing antibiotics (e.g., SMX). Anaerobic SRB granular sludge has recently been successfully applied for wastewater treatment (Hao et al., 2013, Hao et al., 2015). Compared to SRB sludge flocs, SRB granular sludge has potential to shorten the start-up time of SRB sludge system and facilitates better removal of pollutants as higher biomass concentration could be maintained in the system (Hao et al., 2013). In addition, granular sludge has a higher extracellular polymeric substances (EPS) content thereby protecting the microbes against inhibitory compounds including antibiotics (Delgado et al., 2010). Despite the above stated inherent merits, there are limited studies on the use of SRB granular sludge system for antibiotics removal. Even for aerobic granular sludge, very few studies examined the use of aerobic granular sludge system for the removal of micro-pollutants, including antibiotics. For example, Balest et al. (2008) reported that aerobic granular sludge achieved better removal of endocrine disrupting compounds, bisphenol A, and 4-tert-octylphenol (60-90\%) than the CAS process (4172\%). Kang et al. (2018b) found that the removal efficiency of SMX was higher in an anoxic/anaerobic/oxic sequencing batch reactors (SBRs) inoculated with aerobic 
granular activated sludge ( $84 \%)$ than that in the similar system inoculated with suspended aerobic activated sludge ( 73\%). Anaerobic granular sludge has different biological and physical-chemical attributes including redox conditions and microbial community. Thus, there is a need to examine the potential of anaerobic SRB granular sludge systems in treating SMX-laden wastewaters.

Therefore, the objectives of this study were to (a) investigate the effects of SMX on long-term performance of sulfate-reducing upflow sludge bed (SRUSB) reactor inoculated with SRB granules and flocs in terms of organic removal and sulfate reduction; (b) investigate the removal of SMX by the SRUSB reactors during a long-term study; and (c) examine the effects of operational parameters (e.g., $\mathrm{pH}$ and hydraulic retention time (HRT)) on SMX removal in the SRUSB reactors with SRB granular and flocculent sludges. In addition, the fate of SMX in the SRUSB reactors was also examined.

\section{Materials and Methods}

\subsection{Chemicals and reagents}

SMX (99\% purity) was obtained from Dr. Ehrenstorfer Gmbh (Augsburg, Germany). The physical-chemical properties of SMX are presented in supplementary information. $\mathrm{SMX}{ }^{13} \mathrm{C}_{6}$ was purchased from Cambridge Isotope Labscience Inc. (Tewksbury, MA, USA), which was used as an internal standard to determine SMX concentration in samples. Formic acid, and HPLC gradient grade methanol and ethanol were obtained from Merck (Darmstadt, Germany). Oasis HLB cartridges (200 $\mathrm{mg} / 6 \mathrm{~mL}$ ) were purchased from Waters (Milford, MA, USA). Filter membrane (0.22- 
$\mu \mathrm{m})$ was obtained from Jinteng (Tianjin, China). All the standards were prepared using Ultra-pure water from Millipore System (Millipore, Billerica, MA, USA). Two individual standard stock solutions of SMX $(100 \mathrm{mg} / \mathrm{L})$ and $\mathrm{SMX}{ }^{13} \mathrm{C}_{6}(10 \mathrm{mg} / \mathrm{L})$ were prepared in methanol. Both stock solutions were kept in the dark at $4{ }^{\circ} \mathrm{C}$ until further use.

\subsection{SRUSB reactor setup and operation}

Two identical laboratory-scale SRUSB reactors with a working volume of 0.5 $\mathrm{L}$ (40 $\mathrm{mm}$ diameter $\times 500 \mathrm{~mm}$ total height) were fabricated using acrylic (Supplementary material). SRB granules taken from a SRUSB reactor in our laboratory, were used as a seed sludge in one SRUSB reactor in this study, which was continuously operated for more than 200 days. The SRB granules taken from the same SRUSB reactor were disintegrated into flocs and then seeded into another SRUSB reactor. The sludge concentration in the two SRUSB reactors was $7.0 \pm 0.1 \mathrm{~g}$ suspended solids (SS)/L. The properties of the sludge in the two SRUSB reactors are described in Supplementary material. Both SRUSB reactors were fed with synthetic wastewater, and the stock synthetic wastewater was prepared as per Hao et al. (2013). Due to well acclimation of SRB sludge, both sludge systems showed COD and sulfate removal efficiency over $85 \%$ and $75 \%$, respectively, (data not shown here) during a short acclimation period of 10 days without SMX. After the acclimation period, SMX stock solution was spiked periodically into the influent tank to achieve an influent SMX concentration of about $50 \mu \mathrm{g} / \mathrm{L}$ (the measured influent SMX concentration fluctuated slightly, see Fig. 2). The two SRUSB reactors were then 
operated continuously for approximately 150 days during which the influent COD and sulfate concentrations were $498 \pm 38 \mathrm{mg} / \mathrm{L}$ and $222 \pm 12 \mathrm{mg} \mathrm{S} / \mathrm{L}$, respectively. The influent $\mathrm{pH}$ was maintained at $7.0 \pm 0.2$ by adding $0.1 \mathrm{mM} \mathrm{HCl} / \mathrm{NaOH}$ solution using a $\mathrm{pH}$ controller. The HRT in both reactors was maintained at $5 \mathrm{~h}$. The effluent from each reactor was recirculated to the SRUSB reactor with an internal flow recycle ratio at 5:1. The liquid up-flow velocity in each reactor was $0.47 \mathrm{~m} / \mathrm{h}$. The two SRUSB reactors were placed in a temperature-controlled chamber $\left(25 \pm 2{ }^{\circ} \mathrm{C}\right)$ throughout the experiment. During the experiment, influent and effluent samples were periodically collected from both reactors to measure sulfide, total organic carbon (TOC), sulfate, thiosulfate and SMX concentrations, and the effluent $\mathrm{pH}$. Moreover, sludge samples were also periodically collected from the two SRUSB reactors to determine SMX accumulation and EPS content of the sludge.

\subsection{SMX and extracellular polymeric substances (EPS) binding experiment}

EPS play a crucial role in micropollutants removal. This is because proteins as an important component of EPS, have diverse functional groups, such as carboxyl, amine and hydroxyl groups, and hydrophobic regions, which can provide binding sites for the adsorption of micro-pollutants (Sheng et al., 2010, Xu et al., 2013, Wang et al., 2018). There are limited studies on the role of proteins in EPS derived from SRB sludge on the adsorption of SMX. Thus, following the tests described in Section 2.4, a series of binding batch experiments were conducted using the EPS extracted from both SRB granules and flocs from SRUSB reactors at different SMX concentrations to determine which proteins of EPS play an important role on the adsorption of SMX in 
the SRB granular and flocculent sludge systems. Before extracting EPS from the respective sludge samples, the SRUSB reactors were continuously fed with SMX-free synthetic wastewater until SMX concentration was nondetectable in both aqueous and solid phases. The extracted EPS from the SRB granules and flocs, was first purified by polyethersulfone ultrafiltration membrane with 5000 molecular weight cut-off (Millipore, Billerica, MA, USA) to remove ions and small molecules (Xu et al., 2013). The retentate was lyophilized to EPS powder (referred to as pristine EPS) with a freeze dryer (ALPHA Marin Christ, Germany), and stored in a desiccator until further use. In order to obtain a good resolution of excitation-emission matrix (EEM) fluorescence spectra, $50 \mathrm{mg} / \mathrm{L}$ of EPS solution was prepared following the procedure given in Zhang et al. (2018a). Different volumes of SMX stock solution were spiked into each tube containing the EPS solution to obtain a series of different initial concentrations, ranging from $0,100,200,500,1000,1500,2000,2500,3000,3500$, 4000 and $4500 \mu \mathrm{g} / \mathrm{L}$. The initial pH was adjusted to approximately 7.0 by adding 0.1 $\mathrm{mM} \mathrm{HCl}$ or $\mathrm{NaOH}$ solution. All the tubes were mixed for 10 min using oscillator (IKA, Vortex, Germany), and then placed in a dark room for $4 \mathrm{~h}$ at $25 \pm 0.5^{\circ} \mathrm{C}$ to reach adsorption equilibrium before spectral analyses (Zhang et al., 2018a). The details of spectral analysis are described in Chemical analyses section.

\subsection{Effects of $\mathrm{pH}$ and HRT on SMX removal by SRB granules and flocs}

\subsubsection{Test I: Effect of $\mathrm{pH}$ on SMX removal}

The variations in wastewater $\mathrm{pH}$ could affect enzyme activity of microorganisms which is essential for biodegradation of complex organic compounds 
(Grandclement et al., 2017). As such, the removal of SMX in the SRUSB reactors could be influenced by $\mathrm{pH}$. At the end of the experiment (from days 152 to 205), the effects of different initial pH levels on SMX removal were studied in the two SRUSB reactors. As the sewage $\mathrm{pH}$ generally ranges from 6.5 to 8.5 (Qian et al., 2018), a broader $\mathrm{pH}$ ranges of 6.0 to 9.0 were examined in this study (Table 1 ). During each pH condition, the SRUSB reactors were operated for seven days except at $\mathrm{pH} 7.0$ in which the reactors were operated for 5 days. The other operational parameters were kept the same as those described in Section 2.1. During the test, the influent and effluent $\mathrm{pH}$, TOC, sulfate, sulfide and thiosulfate, and SMX concentration in aqueous and sludge samples were measured as discussed in Chemical analyses section.

\subsubsection{Test II: Effects of HRT on SMX removal}

HRT is a critical operating parameter in bioreactor operation. Long HRT on one hand extends the exposure of high concentrations of intermediates that are more toxic than SMX, to microbes in SRUSB reactor; on the other hand, it provides longer time for microbes to degrade the SMX. Thus, the effects of different HRTs (from 5 to $9 \mathrm{~h}$ ) on SMX removal and the treatment performance of the SRUSB reactors were investigated at $\mathrm{pH} 7.0 \pm 0.2$ following the completion of studies of $\mathrm{pH}$ effect. This experiment lasted for 42 days (from days 210 to 251), in which each HRT condition was tested for at least seven days (Table 1). Before the start of test, the SRUSB reactors were continuously operated at $\mathrm{pH} 7.0 \pm 0.2$ for four days to minimize the interference of effect of varying $\mathrm{pH}$ on SMX removal. The other operational parameters were kept the same as those described in Section 2.1. During the test, 
the measured parameters were the same as those described in the Test I.

\subsection{Chemical analyses}

The influent and effluent samples of the SRUSB reactors were collected and filtered through disposable Millipore filter (0.22- $\mu \mathrm{m}$ pore size). The samples were then analyzed for various important parameters such as dissolved sulfide $\left(\mathrm{H}_{2} \mathrm{~S}, \mathrm{HS}^{-}\right.$ and $\left.\mathrm{S}^{2-}\right), \mathrm{pH}$, alkalinity, and total volatile fatty acids (VFAs). TOC was measured instead of COD in this study to eliminate the effect of dissolved sulfide on COD measurement (Zhang et al., 2018b). TOC was analyzed with a TOC analyzer (Shimadzu TOC-5000A, Japan), and the values were converted into equivalent COD based on a theoretical ratio of $2.67 \mathrm{~g}$ COD/g TOC (Liang et al., 2016). Dissolved sulfide was determined by the methylene blue method as per Standard Methods (APHA, 2005). Sulfate and thiosulfate concentrations were quantified using an ion chromatograph (DIONEX900, ICS-900, Fremont, CA, USA) with a conductivity detector and an IC-SA2 analytical column. VFAs and alkalinity were analyzed using the five-point titration method (Moosbrugger et al., 1992). pH was measured with a pH meter (HQ40D). Sludge volume index in $5 \mathrm{~min}\left(\mathrm{SVI}_{5}\right)$, suspended solids (SS), and volatile suspended solids (VSS) were measured following the Standard Methods (APHA, 2005).

During the long-term operation of the SRUSB reactors, EPS contents of sludge granules and flocs on days $0,30,60,90,120$ and 150 were determined. The EPS were extracted from the sludge granules and flocs using $\mathrm{NaOH}$ formaldehyde method described in Bourven et al. (2011). EPS mainly contain proteins (PN) and polysaccharides (PS) (Yang et al., 2016). PN was measured using 
the modified Lowry method (DC protein assay, BioRad, USA) with bovine serum albumin as a standard (Yang et al., 2016). PS was measured using the phenol-sulfuric acid method with glucose as a standard (Yang et al., 2016). The adsorption of SMX onto EPS was analyzed by three-dimensional excitation-emission matrix (3D-EEM) fluorescence spectroscopy technology, which was further visualized by a threedimensional fluorescence spectrophotometer (Aqualog- UV-800-C, HORIBA, Japan). The EEM data were analyzed using MATLAB 2016a (Mathworks, Natick, MA, USA) with DOMFluorl.7 tool-box. Parallel factor analysis (PARAFAC) was used to resolve the EEM data. Determination of the correct number of components was mainly based on residual analysis, split-half analysis, and visual inspection (Zhang et al., 2018a). The details of EEM analysis are described in Zhang et al. (2018a).

The SMX was measured according to the pre-established method as described in Jia et al. (2017). Briefly, the SMX concentration was determined by Ultra Performance Liquid Chromatography (UPLC) equipped with a diode array detection (DAD) detector (Dionex UltiMate 3000, CA, USA) using an Acclaim120 C18 column (2.1 x 150 mm, 3 mm, Dionex, CA, USA) under mobile Phase A (35\% ultra-pure water with $0.1 \%$ formic acid) and mobile Phase B ( $65 \%$ methanol). The operational parameters of the UPLC, limit of detection (LOD) and limit of quantification (LOQ) of the UPLC are based on the analytical methods described in Jia et al. (2017), and the detailed procedures are given in Supplementary material.

\subsection{Statistical analysis}

The statistical analysis was performed in GraphPad Prism 7.0. A Mann-Whitney 
test was used to assess the significant difference of the results between the two SRUSB reactors with granules and flocs at the $95 \%$ confidence level $(p<0.05)$. Oneway Analysis of Variance (ANOVA) was used to find the significant differences among different parameters in the SRUSB reactors with granules and flocs using a 0.05 significance level $(p<0.05)$.

\section{Results and Discussion}

\subsection{Performance of SRUSB reactors}

The two SRUSB reactors inoculated with granules and flocs reached steady state within ten days of operation without SMX addition. Both reactors achieved average COD and sulfate removal efficacy of $85 \%$ and $75 \%$, respectively (data not shown here). The two SRUSB reactors were then continuously operated for nearly 150 days at an initial SMX concentration of $50 \mu \mathrm{g} / \mathrm{L}$ (Fig. 1). In the SRUSB reactor with granules, the settleability $\left(\mathrm{SVI}_{5}=28 \mathrm{~mL} / \mathrm{g}\right)$ and size $(\sim 620 \mu \mathrm{m})$ of SRB granules did not change substantially during the entire operational period, and the sludge concentration gradually increased from $7.06 \pm 0.01 \mathrm{~g} \mathrm{SS} / \mathrm{L}$ on day 0 to $10.08 \pm 0.02 \mathrm{~g}$ SS/L on day 150 (Supplementary material). The COD and sulfate removal efficiency remained stable, and were similar to those in the acclimation period without SMX. The results apparently showed that the presence of SMX did not affect the performance of SRUSB reactor with granules. In the SRUSB reactor with flocs, flocs size $(\sim 81 \mu \mathrm{m})$ and sludge concentration $(6.94 \pm 0.02 \mathrm{~g} \mathrm{SS} / \mathrm{L})$ did not change significantly during the first 30 days of operation. During the same time period, COD 
and sulfate removal efficiency decreased to $75 \pm 3 \%$ and $62 \pm 4 \%$, respectively (Fig. 1b). The results suggest that SMX had an inhibitory effect on SRB flocs at the beginning of the reactor operation. The COD and sulfate removal efficiency, however, gradually recovered to the levels similar to that in the SRUSB reactor with granules. Thus, the SRB were able to gradually adapt to SMX with time. The flocs size and sludge concentration also gradually increased to $\sim 147 \mu \mathrm{m}$ and $9.41 \pm 0.17 \mathrm{~g} \mathrm{SS} / \mathrm{L}$, respectively (Supplementary material).

Furthermore, fluorescence in situ hybridization (FISH) analysis results showed that SRB abundance in the granules and flocs did not decrease during the long-term operation with SMX addition of $50 \mu \mathrm{g} / \mathrm{L}$ (see Supplementary material). The performance of the two SRUSB reactors was similar to that of a full-scale SANI system (Wu et al., 2016). Unlike the SRUSB reactor with flocs, the performance of SRUSB reactor with granules did not decrease from the starting of the reactor operation, indicating that the SRB granules showed a higher tolerance to SMX than the SRB flocs. This could be due to the fact that the SRB granules had a higher content of EPS than the SRB flocs (see Section 3.4), thereby protecting the SRB community against the inhibitory effect of SMX (Schmidt et al., 2012).

\subsection{Removal of SMX in SRUSB reactors}

The measured SMX concentration in the influent was $48.0 \pm 4.9 \mu \mathrm{g} / \mathrm{L}$ during 150 days of SRUSB reactors operation (Fig. 2). During the first 15 days of operation, the SMX removal efficiencies in the SRUSB with granules and flocs were $30 \pm 3 \%$ and $22 \pm 5 \%$, respectively. Starting from day 15 , the SMX removal efficiency in SRUSB 
reactors with granules and flocs gradually increased to $51 \pm 4 \%$ and $40 \pm 3 \%$, respectively, and then remained fairly stable during the rest of the operation. Overall, SRUSB reactor with granules achieved significantly higher SMX removal $(p<0.05)$ than the SRUSB reactor with flocs. The specific SMX removal rate in the SRUSB reactor with granules was also significantly greater $(13.3 \mu \mathrm{g} / \mathrm{g}$ SS-d) than that in the SRUSB reactor with flocs $(11.2 \mu \mathrm{g} / \mathrm{g}$ SS-d) during the steady-state operation $(p<0.001)$. The higher SMX removal by the SRB granules could be attributed to the longer solids retention time (SRT) of the granular system (92 $\pm 1 \mathrm{~d}$ ) than that of suspended sludge (flocs) system (76 $\pm 2 \mathrm{~d}$ ). Long SRT could improve the removal of pharmaceutical compounds by facilitating the growth of diverse microbial community in the granules and retaining the slow-growing bacteria which may have the ability to degrade organic micro-pollutants (Grandclement et al., 2017).

Several studies examined the removal of SMX in activated sludge system (aerobic, anoxic and anaerobic compartments), and the removal was primarily via biodegradation and sorption processes (Rosal et al., 2010, Alvarino et al., 2014, Alvarino et al., 2016, Kang et al., 2018b). However, studies on SMX removal in SRB sludge system, especially in SRB granule system are very limited. Jia et al. (2017) reported SMX removal of around 34\% by SRB flocs at an initial concentration of 100 $\mu \mathrm{g} / \mathrm{L}$, and the specific SMX removal rate was $15.2 \mu \mathrm{g} / \mathrm{g}$ SS- $\mathrm{d}$, which is comparable to that found in this study. The specific SMX removal rates obtained in the anaerobic SRB granule and floc systems in this study were significantly higher than those reported in the CAS processes (1.4-2.2 $\mu \mathrm{g} / \mathrm{g}$ SS-d) (Alvarino et al., 2014, Kang et al., 
2018b), and upflow anaerobic sludge blanket (UASB) reactor (methanogenic process, $0.22 \mu \mathrm{g} / \mathrm{g}$ SS-d) (Alvarino et al., 2014), and were comparable to that obtained in aerobic or anoxic membrane bioreactors (MBR) (0.019-48.8 $\mu \mathrm{g} / \mathrm{g}$ SS-d) (Clara et al., 2005, Hai et al., 2011, Prasertkulsak et al., 2016).

The difference in SMX removal rates between the SRB sludge system and other biological systems could be attributed to the biodegradation rather than the sorption process. SRB (e. g, Desulfobulbus, Desulfobacter and Desulfomicrobium) are the predominant microbial community in the anaerobic SRUSB reactors (Hao et al., 2013, Jiang et al., 2013, Hao et al., 2015, Zhang et al., 2016), and are significantly different from those in aerobic (e. g., Nitrosomonas, Pseudomonas, and Acinetobacter). (Kang et al., 2018a) and anaerobic (e.g., Clostridium) systems treating SMX-laden wastewater. Moreover, SMX has a low octanol-water distribution coefficient $\left(\log K_{\text {ow }}=0.86\right)$, and is therefore more hydrophilic and is difficult to be sorbed (Chen et al., 2011, Hyland et al., 2012). Jia et al. (2017) also reported that only a small fraction of SMX ( 9.1\%) was sorbed by inactivated anaerobic SRB sludge (flocs) at an initial concentration of $50 \mu \mathrm{g} / \mathrm{L}$. In another study by Yang et al. (2011), $7.2 \%$ of SMX was adsorbed by sterilized aerobic activated sludge at an initial concentration of $100 \mu \mathrm{g} / \mathrm{L}$.

\subsection{Fate of SMX in the SRUSB reactors with granules and flocs}

Microbial degradation, hydrolysis, volatilization, photodegradation, and sorption are the different possible pathways of organic micro-pollutants removal in activated sludge systems (Grandclement et al., 2017). Hydrolysis and volatilization 
can be neglected based on the physical-chemical properties of SMX.

Photodegradation can also be ruled out as the SRUSB reactors were always covered with aluminum foil. Therefore, the main removal pathways in the SRUSB reactors could be via biodegradation and sorption processes.

As shown in Fig. 3, the accumulated SMX in the SRB granules and flocs were $24.2 \pm 0.4 \mathrm{mg} / \mathrm{kg} \mathrm{SS}$ and $19.5 \pm 0.4 \mathrm{mg} / \mathrm{kg} \mathrm{SS}$, respectively, during the first ten days of SRUSB reactors operation, and both sludges showed decreasing trend and reached nearly stable values after 50 days of operation. At the end of operation (150 days), the SMX concentrations accumulated in the SRUSB reactors with granules and flocs were $12.5 \pm 0.3 \mathrm{mg} / \mathrm{kg}$ SS and $10.9 \pm 0.2 \mathrm{mg} / \mathrm{kg}$ SS, respectively. The results apparently showed that SMX biodegradation improved with time as apparent from higher contribution of biodegradation over adsorption to SMX removal during longterm operation of SRUSB reactors. Based on mass balance, $23.8 \%$ and $24.1 \%$ of the removed SMX were attributed to sorption process in the SRUSB reactors with SRB granules and flocs, respectively, during the first ten days. The contribution of sorption on SMX removal decreased with time, and the contribution of sorption on SMX removal during entire operational period (150 days) was only $0.8 \%$ and $0.9 \%$ of the removed SMX in the SRUSB reactors with SRB granules and flocs, respectively. The results apparently indicate that biodegradation was the main pathway of SMX removal during the long-term operation. Jia et al. (2017) observed that $93 \%$ of SMX was biodegraded by SRB flocs at an initial concentration of $50 \mu \mathrm{g} / \mathrm{L}$. In aerobic activated sludge systems, Kang et al. (2018b) found that SMX removal by aerobic 
granules and CAS was mainly attributed to biodegradation. It should be noted that, although SMX removal was mainly attributed to biodegradation in the SRUSB reactors, sorption also played an important role on SMX removal process (Jia et al., 2017). The authors reported that SMX removal by SRB flocs was characterized by a rapid sorption followed by desorption until reaching equilibrium, and then followed by slow biodegradation.

\subsection{Roles of EPS on SMX removal in the SRB sludge system}

EPS were extracted periodically from the SRB granules and flocs during longterm operation of SRUSB reactors at different SMX concentrations (Fig. 4). In the SRUSB reactor with granules, the EPS content increased slightly from $106.0 \pm 0.7$ $\mathrm{mg} / \mathrm{g}$ VSS on day 0 to $112.8 \pm 1.1 \mathrm{mg} / \mathrm{g}$ VSS on day 30 , and then remained fairly stable during the rest of operation. In the SRUSB reactor with flocs, the EPS content increased significantly from $49.7 \pm 0.7 \mathrm{mg} / \mathrm{g}$ VSS on day 0 to $68.8 \pm 0.3 \mathrm{mg} / \mathrm{g}$ VSS on day 30 and reached a plateau. The increase in EPS content could be due to the fact that microbes secrete more EPS to protect against the toxic compounds such as antibiotics (Schmidt et al., 2012, Zhang et al., 2018a). A less increase in EPS content in SRB granules over SRB flocs shows that SRB granules with higher EPS content had a higher tolerance to SMX than SRB flocs. Zhang et al. (2018a) also observed higher EPS content in SRB sludge system with increasing ciprofloxacin (CIP) concentration.

The mass ratio of proteins-to-polysaccharides (PN/PS) in EPS is an important factor influencing the adsorption of micro-pollutants as PN/PS ratio can be used as an indicator of hydrophobicity (Xu et al., 2013). Thus, EPS with higher PN/PS 
ratio have stronger hydrophobicity and provide more adsorption sites (Xu et al., 2013). As shown in Fig. 4, the PN/PS ratios in the SRB granules were significantly higher than that in the SRB flocs $(p<0.05)$, indicating that the EPS in the SRB granules have a greater capacity to adsorb SMX than that of SRB flocs. This finding was in consistent with the sorption results in which the accumulated SMX concentration in the SRB granules was significantly higher than that in the SRB flocs throughout the operation of SRUSB reactors (Fig. 4).

The 3D-EEM fluorescence spectra of EPS extracted from SRB granules at the end of experiment was analyzed as shown in Fig. 5. Three main components of EPS were identified at excitation/emission: 230/296-305 nm (Peak a), 215-225/355-367 $\mathrm{nm}$ (Peak b) and 220/342-349 nm (Peak c). The peaks a, $\mathrm{b}$ and $\mathrm{c}$ were assigned to the peaks of tryptophan, tyrosine, and aromatic protein-like substances, respectively. The compositions of EPS extracted from SRB flocs were similar to that extracted from SRB granules. Binding experiments between EPS and SMX were also performed to determine which proteins significantly influenced the adsorption of SMX onto EPS (see Supplementary material). The results showed that only the fluorescence intensity of aromatic protein-like substances in both granules and flocs significantly changed with increased SMX concentration indicating that aromatic protein-like substances played an important role on SMX adsorption by EPS. Gu et al. (2017) also reported that the fluorescence intensities of protein-like substances of EPS extracted from aerobic biofilms in wastewater treatment systems including aromatic proteinlike substances increased with increasing CIP concentration. This study for the first 
time demonstrated the role of aromatic protein-like substances of EPS on SMX adsorption by SRB granules.

\subsection{Operational parameters influencing SMX removal}

\subsection{1. $\mathrm{pH}$}

The results apparently showed that COD and sulfate removals were stable under different influent $\mathrm{pH}$ levels (see Supplementary material), which were also similar to those observed in the long-term operation of SRUSB reactors (Fig. 1). Thus, the SRB activity was not affected at the $\mathrm{pH}$ range of 6.0-9.0, which is in consistent with studies by Widdel et al. (1983) and Hao et al. (2016), who also reported that SRB activity did not change at $\mathrm{pH}$ range of 6.0-9.0. However, with decreasing influent pH from 7.0 to 6.0 in the SRUSB reactors, SMX removal gradually declined (Fig. 5a). In detail, SMX removal in the SRUSB reactor with granules significantly decreased from $51 \% \pm 2$ at $\mathrm{pH} 7.0$ to $42 \pm 3 \%$ at $\mathrm{pH} 6.0(p=0.001)$. In the SRUSB reactor with flocs, the $\mathrm{SMX}$ removal reduced significantly from $41 \pm 1 \%$ at $\mathrm{pH} 7.0$ to $22 \pm 5 \%$ at $\mathrm{pH} 6.0$ $(p=0.0003)$. When the influent $\mathrm{pH}$ was increased to 7.0 , the SMX removal in both reactors recovered to the original levels (Fig. 6). When the influent $\mathrm{pH}$ was further increased to 9.0 in both SRUSB reactors, the SMX removal remained fairly stable. The results suggest that $\mathrm{SRB}$ granules possess higher resilience against varying $\mathrm{pH}$ than the SRB flocs.

Although the $\log D(D$ : distribution-coefficient) of SMX could be influenced by the varying $\mathrm{pH}$, even with increasing $\mathrm{pH}$ from 6.0 to 9.0 , the $\log \mathrm{D}$ of SMX only declined slightly from 0.60 at $\mathrm{pH} 6.0$ to -0.15 at pH 9.0 (see Supplementary material). It apparently shows that the effect of varying $\mathrm{pH}$ on SMX adsorption capacity of SRB 
sludge was negligible, which is in consistent with the SMX adsorbed onto the sludge at different $\mathrm{pH}$ levels (see Supplementary material). Therefore, the decrease in SMX removal at low pH levels (6.0 and 6.5) could be mainly attributed to the low biodegradation of SMX by the SRB at $\mathrm{pH}$ range of 6.0-6.5. However, the SRB activity in terms of COD removal and sulfate reduction was not affected at the $\mathrm{pH}$ range of 6.0-6.5. Thus, some functional genes and enzymes responsible for SMX biodegradation in the SRB were likely inhibited at a low $\mathrm{pH}$, which merits further investigation.

\subsubsection{HRT}

The SRUSB reactors with granules and flocs removed $49 \pm 2 \%$ and $39 \pm 2 \%$ of the influent SMX, respectively at an initial concentration of $50 \mu \mathrm{g} / \mathrm{L}$ at HRT of $5 \mathrm{~h}$ (Fig. 6). Again, SRB granules achieved significantly higher SMX removal than SRB flocs regardless of varying HRTs from 5 to $9 \mathrm{~h}(p<0.001)$ (Fig. 6). As for the SRB granules, SMX removal gradually increased to $61 \pm 1 \%$ when the HRT was increased to $7 \mathrm{~h}$ and then remained nearly stable with further increase in HRT to $9 \mathrm{~h}$. The accumulated SMX in the sludge was similar among the different HRTs $(12.4 \pm 0.2 \mathrm{mg} / \mathrm{kg} \mathrm{SS})$ (see Supplementary material), indicating that longer HRT facilitated SMX biodegradation. In addition, COD and sulfate removals remained stable when the HRT was increased from 5 to $9 \mathrm{~h}$. In the SRUSB reactor with flocs, removal of SMX (41 $\pm 2 \%)$ and the accumulated SMX $(10.2 \pm 0.2 \mathrm{mg} / \mathrm{kg} \mathrm{SS})$ in the flocs did not change significantly when the HRT was increased from 5 to $9 \mathrm{~h}$. However, the treatment performance of the SRUSB reactor with flocs showed a decreasing trend in terms of COD removal and 
sulfate reduction when the HRT was higher than $7 \mathrm{~h}$ (see Supplementary material), indicating that SRB activity decreased when HRT was longer than $7 \mathrm{~h}$. The decrease in SRB activity could be attributed to the increasing toxicity caused by the formation of intermediates from SMX biodegradation (Protocols and results are described in Supplementary material). Notably, SMX removal was expected to decrease when HRT was higher than $7 \mathrm{~h}$ owing to the decreased SRB activity. In contrast, the SMX removal during these conditions remained fairly stable. It may be due to the fact that a longer HRT allowed a longer reaction time, which has likely overcome the negative effect of decreased SRB activity on SMX removal to some extent. The result also demonstrates that SRB granules had a higher resilience against the variations of HRT than the SRB flocs.

\subsection{Practical implications}

Previous studies reported that CAS and anaerobic (methanogenic) processes as well as MBR could remove SMX from wastewater (Clara et al., 2005, Hai et al., 2011, Alvarino et al., 2014, Alvarino et al., 2016, Prasertkulsak et al., 2016, Kang et al., 2018b). According to the discussion in Section 3.2, the SMX removal rates in these processes were significantly lower than that obtained in SRB-mediated process especially in the SRB granular sludge system except for MBR. Although MBR can achieve similar or higher SMX removal rate than the SRB-mediated process, the capital and operational costs of MBR systems are generally higher due to costs associated with membrane fouling control and frequent replacement of membrane (Grandclement et al., 2017). SRB-mediated process can also effectively remove COD 
from wastewater with lower energy consumption and less sludge production compared to CAS process (Lu et al., 2012, Wu et al., 2016). Further studies on assessing the extended application of SRB-mediated process for removing other antibiotics, such as isoxazole-containing compounds should also be conducted. Additionally, SRB-mediated process could produce high amount of sulfide, an odorous gas, which can cause corrosion of metals and concrete. Additional processes may be needed to remove or convert the formed sulfide into benign form such as elemental sulfur or sulfate (van den Bosch et al., 2007, Zhang et al., 2018c).

\section{Conclusions}

This study investigated and compared SMX removal by SRB granules and flocs in SRUSB reactors under the same operational conditions for 150 days. SMX removal by SRB granules (13.3 $\mu \mathrm{g} / \mathrm{g}$ SS-d) was significantly higher than that by SRB flocs (11.2 $\mu \mathrm{g} / \mathrm{g}$ SS-d) $(p<0.05)$. SMX had no significant effect on COD and sulfate removals in the two reactors. Biodegradation was the main pathway for SMX removal in the SRB sludge system. SRB granules had a better resilience against varying $\mathrm{pHs}$ and HRTs than SRB flocs. Collectively, SRB granular sludge system could be employed to efficiently remove SMX from various SMX-laden wastewaters.

Appendix A: Supplementary Information

Supplementary information can be found in the online version.

\section{Acknowledgment}


We gratefully acknowledge the financial supports from the Natural Science

Foundation of China (No. 51638005 and 51778643) and the Tip-top Scientific and

Technical Innovative Youth Talents of Guangdong Special Support Program (No.

2016TQ03Z336).

\section{References}

1. Alvarino, T., Nastold, P., Suarez, S., Omil, F., Corvini, P. and Bouju, H. (2016) Role of biotransformation, sorption and mineralization of 14 C-labelled sulfamethoxazole under different redox conditions. Sci. Total Environ. 542, 706-715.

2. Alvarino, T., Suarez, S., Lema, J. and Omil, F. (2014) Understanding the removal mechanisms of PPCPs and the influence of main technological parameters in anaerobic UASB and aerobic CAS reactors. J. Hazard. Mater. 278, 506-513.

3. APHA (2005) Standard methods for the examination of water \& wastewater, 21st ed. American Public Health Association (APHA)/American Water Works Association (AWWA)/Water Environment Federation (WEF), Washington, DC, USA.

4. Balest, L., Lopez, A., Mascolo, G. and Di laconi, C. (2008) Removal of endocrine disrupter compounds from municipal wastewater using an aerobic granular biomass reactor. Biochem. Eng. J. 41(3), 288-294.

5. Bourven, I., Joussein, E. and Guibaud, G. (2011) Characterisation of the mineral fraction in extracellular polymeric substances (EPS) from activated sludges 
extracted by eight different methods. Bioresour. Technol. 102(14), 7124-7130.

6. Chen, H., Gao, B. and Li, H. (2015) Removal of sulfamethoxazole and ciprofloxacin from aqueous solutions by graphene oxide. J. Hazard. Mater. 282, 201-207.

7. Chen, H., Gao, B., Li, H. and Ma, L.Q. (2011) Effects of pH and ionic strength on sulfamethoxazole and ciprofloxacin transport in saturated porous media. J. Contam. Hydrol. 126(1-2), 29-36.

8. Clara, M., Strenn, B., Gans, O., Martinez, E., Kreuzinger, N. and Kroiss, H. (2005) Removal of selected pharmaceuticals, fragrances and endocrine disrupting compounds in a membrane bioreactor and conventional wastewater treatment plants. Water Res. 39(19), 4797-4807.

9. Delgado, L.F., Schetrite, S., Gonzalez, C. and Albasi, C. (2010) Effect of cytostatic drugs on microbial behaviour in membrane bioreactor system. Bioresour. Technol. 101(2), 527-536.

10. Falås, P., Wick, A., Castronovo, S., Habermacher, J., Ternes, T.A. and Joss, A. (2016) Tracing the limits of organic micropollutant removal in biological wastewater treatment. Water Res. 95, 240-249.

11. Grandclement, C., Seyssiecq, I., Piram, A., Wong-Wah-Chung, P., Vanot, G., Tiliacos, N., Roche, N. and Doumenq, P. (2017) From the conventional biological wastewater treatment to hybrid processes, the evaluation of organic micropollutant removal: a review. Water Res. 111, 297-317.

12. Gu, C., Gao, P., Yang, F., An, D., Munir, M., Jia, H., Xue, G. and Ma, C. (2017) Characterization of extracellular polymeric substances in biofilms under long- 
term exposure to ciprofloxacin antibiotic using fluorescence excitationemission matrix and parallel factor analysis. Environ. Sci. Pollut. Res. 24(15), $13536-13545$.

13. Hai, F.I, Li, X., Price, W.E. and Nghiem, L.D. (2011) Removal of carbamazepine and sulfamethoxazole by MBR under anoxic and aerobic conditions. Bioresour. Technol. 102(22), 10386-10390.

14. Hao, T., Luo, J., Wei, L., Mackey, H.R., Liu, R., Morito, G.R. and Chen, G.-H. (2015) Physicochemical and biological characterization of long-term operated sulfate reducing granular sludge in the SANI ${ }^{\circledR}$ process. Water Res. 71, 74-84.

15. Hao, T., Mackey, H.R., Guo, G., Liu, R. and Chen, G. (2016) Resilience of sulfatereducing granular sludge against temperature, $\mathrm{pH}$, oxygen, nitrite, and free nitrous acid. Appl. Microbiol. Biotechnol. 100(19), 8563-8572.

16. Hao, T., Wei, L., Lu, H., Chui, H., Mackey, H.R., van Loosdrecht, M. and Chen, G. (2013) Characterization of sulfate-reducing granular sludge in the SANI process. Water Res. 47(19), 7042-7052.

17. Heberer, T. (2002) Occurrence, fate, and removal of pharmaceutical residues in the aquatic environment: a review of recent research data. Toxicol. Lett. 131(1-2), 5-17.

18. Hyland, K.C., Dickenson, E.R., Drewes, J.E. and Higgins, C.P. (2012) Sorption of ionized and neutral emerging trace organic compounds onto activated sludge from different wastewater treatment configurations. Water Res. 46(6), 19581968. 
19. Jia, Y., Khanal, S.K., Shu, H., Zhang, H., Chen, G.-H. and Lu, H. (2018) Ciprofloxacin degradation in anaerobic sulfate-reducing bacteria (SRB) sludge system: Mechanism and pathways. Water Res. 136, 64-74.

20. Jia, Y., Khanal, S.K., Zhang, H., Chen, G.-H. and Lu, H. (2017) Sulfamethoxazole degradation in anaerobic sulfate-reducing bacteria sludge system. Water Res. $119,12-20$.

21. Jiang, F., Zhang, L., Peng, G.-L., Liang, S.-Y., Qian, J., Wei, L. and Chen, G.-H. (2013) A novel approach to realize SANI process in freshwater sewage treatmentUse of wet flue gas desulfurization waste streams as sulfur source. Water Res. 47(15), 5773-5782.

22. Joss, A., Keller, E., Alder, A.C., Göbel, A., McArdell, C.S., Ternes, T. and Siegrist, H. (2005) Removal of pharmaceuticals and fragrances in biological wastewater treatment. Water Res. 39(14), 3139-3152.

23. Kang, A.J., Brown, A.K., Wong, C.S., Huang, Z. and Yuan, Q. (2018a) Variation in bacterial community structure of aerobic granular and suspended activated sludge in the presence of the antibiotic sulfamethoxazole. Bioresour. Technol. $261,322-328$.

24. Kang, A.J., Brown, A.K., Wong, C.S. and Yuan, Q. (2018b) Removal of antibiotic sulfamethoxazole by anoxic/anaerobic/oxic granular and suspended activated sludge processes. Bioresour. Technol. 251, 151-157.

25. Li, W., Niu, Q., Zhang, H., Tian, Z., Zhang, Y., Gao, Y., Li, Y.-Y., Nishimura, O. and Yang, M. (2015) UASB treatment of chemical synthesis-based pharmaceutical 
wastewater containing rich organic sulfur compounds and sulfate and associated microbial characteristics. Chem. Eng. J. 260, 55-63.

26. Liang, S., Zhang, L. and Jiang, F. (2016) Indirect sulfur reduction via polysulfide contributes to serious odor problem in a sewer receiving nitrate dosage. Water Res. 100, 421-428.

27. Lu, H., Wu, D., Jiang, F., Ekama, G.A., van Loosdrecht, M. and Chen, G.H. (2012) The demonstration of a novel sulfur cycle - based wastewater treatment process: Sulfate reduction, autotrophic denitrification, and nitrification integrated $\left(\mathrm{SANI}^{\circledR}\right)$ biological nitrogen removal process. Biotechnol. Bioeng. 109(11), 2778-2789.

28. Mohan, S.V., Rao, N.C., Prasad, K.K. and Sarma, P. (2005) Bioaugmentation of an anaerobic sequencing batch biofilm reactor (AnSBBR) with immobilized sulphate reducing bacteria (SRB) for the treatment of sulphate bearing chemical wastewater. Process Biochem. 40(8), 2849-2857.

29. Moosbrugger, R., Wentzel, M., Ekama, G. and Marais, G. (1992) Simple titration procedures to determine $\mathrm{H}_{2} \mathrm{CO}_{3}$ * alkalinity and short-chain fatty acids in aqueous solutions containing known concentrations of ammonium, phosphate and sulphide weak acid/bases. Water Research Commission, Report No. TT 57, 92.

30. Prasertkulsak, S., Chiemchaisri, C., Chiemchaisri, W., Itonaga, T. and Yamamoto, K. (2016) Removals of pharmaceutical compounds from hospital wastewater in membrane bioreactor operated under short hydraulic retention time. 
Chemosphere 150, 624-631.

31. Qian, J., Zhang, M., Wu, Y., Niu, J., Chang, X., Yao, H., Hu, S. and Pei, X. (2018) A feasibility study on biological nitrogen removal (BNR) via integrated thiosulfate-driven denitratation with anammox. Chemosphere 208, 793-799.

32. Rosal, R., Rodríguez, A., Perdigón-Melón, J.A., Petre, A., García-Calvo, E., Gómez, M.J., Agüera, A. and Fernández-Alba, A.R. (2010) Occurrence of emerging pollutants in urban wastewater and their removal through biological treatment followed by ozonation. Water Res. 44(2), 578-588.

33. Schmidt, S., Winter, J. and Gallert, C. (2012) Long-term effects of antibiotics on the elimination of chemical oxygen demand, nitrification, and viable bacteria in laboratory-scale wastewater treatment plants. Arch. Environ. Contam. Toxicol. 63(3), 354-364.

34. Sheng, G.-P., Yu, H.-Q. and Li, X.-Y. (2010) Extracellular polymeric substances (EPS) of microbial aggregates in biological wastewater treatment systems: a review. Biotechnol. Adv. 28(6), 882-894.

35. van den Bosch, P.L., van Beusekom, O.C., Buisman, C.J. and Janssen, A.J. (2007) Sulfide oxidation at halo-alkaline conditions in a fed-batch bioreactor. Biotechnol. Bioeng. 97(5), 1053-1063.

36. Wang, L., Li, Y., Wang, L., Zhu, M., Zhu, X., Qian, C. and Li, W. (2018) Responses of biofilm microorganisms from moving bed biofilm reactor to antibiotics exposure: Protective role of extracellular polymeric substances. Bioresour. Technol. 254, 268-277. 
37. Widdel, F., Kohring, G.-W. and Mayer, F. (1983) Studies on dissimilatory sulfatereducing bacteria that decompose fatty acids. Arch. Microbiol. 134(4), 286294.

38. Wu, D., Ekama, G.A., Chui, H.-K., Wang, B., Cui, Y.-X., Hao, T.-W., van Loosdrecht, M.C. and Chen, G.-H. (2016) Large-scale demonstration of the sulfate reduction autotrophic denitrification nitrification integrated $\left(\mathrm{SANI}^{\circledR}\right)$ process in saline sewage treatment. Water Res. 100, 496-507.

39. Xu, B., Mao, D., Luo, Y. and Xu, L. (2011) Sulfamethoxazole biodegradation and biotransformation in the water-sediment system of a natural river. Bioresour. Technol. 102(14), 7069-7076.

40. Xu, J., Sheng, G.-P., Ma, Y., Wang, L.-F. and Yu, H.-Q. (2013) Roles of extracellular polymeric substances (EPS) in the migration and removal of sulfamethazine in activated sludge system. Water Res. 47(14), 5298-5306.

41. Yang, S.-F., Lin, C.-F., Lin, A.Y.-C. and Hong, P.-K.A. (2011) Sorption and biodegradation of sulfonamide antibiotics by activated sludge: experimental assessment using batch data obtained under aerobic conditions. Water Res. 45(11), 3389-3397.

42. Yang, W., Lu, H., Khanal, S.K., Zhao, Q., Meng, L. and Chen, G.-H. (2016) Granulation of sulfur-oxidizing bacteria for autotrophic denitrification. Water Res. 104, 507-519.

43. Zhang, H., Jia, Y., Khanal, S.K., Lu, H., Fang, H. and Zhao, Q. (2018a) Understanding the role of extracellular polymeric substances (EPS) on ciprofloxacin (CIP) 
adsorption in aerobic sludge, anaerobic sludge and sulfate-reducing bacteria (SRB) sludge systems. Environ. Sci. Technol. 52(11), 6476-6486.

44. Zhang, L., Lin, X., Wang, J., Jiang, F., Wei, L., Chen, G. and Hao, X. (2016) Effects of Lead and Mercury on Sulfate-Reducing Bacterial Activity in a Biological Process for Flue Gas Desulfurization Wastewater Treatment. Sci. Rep. 6.

45. Zhang, L., Lin, X., Zhang, Z., Chen, G.-H. and Jiang, F. (2018b) Elemental sulfur as an electron acceptor for organic matter removal in a new high-rate anaerobic biological wastewater treatment process. Chem. Eng. J. 331, 16-22.

46. Zhang, S., Yang, X.-L., Li, H., Song, H.-L., Wang, R.-C. and Dai, Z.-Q. (2017) Degradation of sulfamethoxazole in bioelectrochemical system with power supplied by constructed wetland-coupled microbial fuel cells. Bioresour. Technol. 244, 345-352.

47. Zhang, Y., Zhang, L., Li, L., Chen, G.-H. and Jiang, F. (2018c) A novel elemental sulfur reduction and sulfide oxidation integrated process for wastewater treatment and sulfur recycling. Chem. Eng. J. 342, 438-445.

48. Zuccato, E., Castiglioni, S., Bagnati, R., Melis, M. and Fanelli, R. (2010) Source, occurrence and fate of antibiotics in the Italian aquatic environment. J. Hazard. Mater. 179(1-3), 1042-1048. 